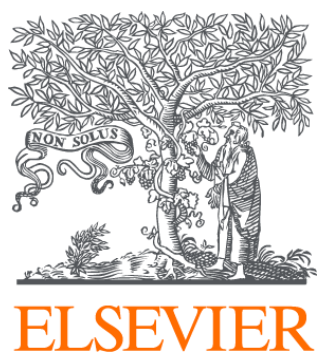

Since January 2020 Elsevier has created a COVID-19 resource centre with free information in English and Mandarin on the novel coronavirus COVID-

19. The COVID-19 resource centre is hosted on Elsevier Connect, the company's public news and information website.

Elsevier hereby grants permission to make all its COVID-19-related research that is available on the COVID-19 resource centre - including this research content - immediately available in PubMed Central and other publicly funded repositories, such as the WHO COVID database with rights for unrestricted research re-use and analyses in any form or by any means with acknowledgement of the original source. These permissions are granted for free by Elsevier for as long as the COVID-19 resource centre remains active. 


\title{
Respiratory viruses, a common microbiological finding in neutropenic children with fever
}

\author{
Anna Lindbloma,*, Vivek Bhadri ${ }^{\mathrm{b}}$, Stefan Söderhällc ${ }^{\mathrm{c}}$, Lars Öhrmalm ${ }^{\mathrm{a}}$, Michelle Wonga, \\ Oscar Norbeck ${ }^{\mathrm{a}}$, Cecilia Lindau $^{\mathrm{d}}$, Maria Rotzén-Östlund ${ }^{\mathrm{d}}$, Tobias Allander ${ }^{\mathrm{d}}$, Daniel Catchpoole ${ }^{\mathrm{e}}$, \\ Luciano Dalla-Pozza ${ }^{\mathrm{b}}$, Kristina Broliden ${ }^{\mathrm{a}}$, Thomas Tolfvenstam ${ }^{\mathrm{a}}$ \\ a Unit of Infectious Diseases, Department of Medicine, Solna, and Center for Molecular Medicine, Karolinska Institutet, Karolinska University Hospital, Stockholm, Sweden \\ ${ }^{\mathrm{b}}$ Paediatric Oncology Unit, The Children's Hospital at Westmead, Sydney, Australia \\ ${ }^{\mathrm{c}}$ Childhood Cancer Unit, Department of Woman and Child Health, Karolinska Institutet, Karolinska University Hospital, Stockholm, Sweden \\ ${ }^{\mathrm{d}}$ Department of Microbiology Tumor and Cell Biology, Karolinska Institutet, and Department of Clinical Microbiology, Karolinska University Hospital, Stockholm, Sweden \\ e The Tumour Bank, The Children's Hospital at Westmead, Sydney, Australia
}

\section{A R T I C L E I N F O}

\section{Article history:}

Received 24 June 2009

Received in revised form

24 November 2009

Accepted 29 November 2009

\section{Keywords:}

Viral infections

Neutropenia

Fever

Pediatrics

\begin{abstract}
A B S T R A C T
Background: Febrile neutropenia is a common complication in children undergoing chemotherapy for malignancies. A microbial agent is only identified in $15-30 \%$ of the fever episodes and corresponds mostly to bacterial findings.

Objective: To investigate viral infections as possible etiologic agents in episodes of febrile neutropenia. Study design: Nasopharyngeal aspirates (NPAs) from patients presenting with neutropenic fever at two pediatric oncology wards in Sweden and Australia were analyzed with a conventional virus-diagnostic approach and RT-PCR. Coupled blood samples were analyzed for the detection of CMV, EBV, adenovirus and erythrovirus. Bacterial blood culture was performed routinely.

Results: Conventional virus-diagnostic approach coupled to routinely performed bacterial analyzes revealed an infectious agent in $29 \%$ compared to $60 \%$ when using PCR. By adding PCR, a viral pathogen was detected in $46 \%$ of the NPAs and in $4 \%$ of the blood samples collected. In half of the patients with bacteremia, respiratory tract viruses were co-detected.

Conclusion: Respiratory viruses were frequently detected in NPAs suggesting a significant role of viral infections in children presenting with neutropenic fever. The meaning of these findings needs to be further evaluated but has the potential to individualize infection treatment and to reduce the extensive use of antibiotics in immunocompromised children with neutropenia.
\end{abstract}

(c) 2009 Elsevier B.V. All rights reserved.

\section{Background}

Infections are the major cause of morbidity and mortality in children experiencing neutropenia secondary to chemotherapy. Identification of neutropenic episodes and the use of promptly administered empiric broad spectrum antibiotics has reduced

Abbreviations: AdV, adenovirus; B19, erythrovirus B19; HboV, bocavirus; CMV, cytomegalovirus; CRP, C-reactive protein; EBV, Epstein-Barrvirus; EV, enterovirus; $\mathrm{G}^{+}$, Gram positive bacteria; $\mathrm{G}^{-}$, Gram negative bacteria; HKU1, coronavirus HKU1; MPV, humant metapneumovirus; HRV, humant rhinovirus; KIPyV, KI polyomavirus; NL63, coronavirus NL63; NPA, nasopharyngeal aspirate; OC43, coronavirus OC43; PIV3, parainfluenzaevirus 3; RSV, respiratory syncytial virus; URTS, upper respiratory tract symptoms; WUPyV, WU polyomavirus.

* Corresponding author at: Center for Molecular Medicine, L8:01, Karolinska University Hospital, Solna, S-171 76 Stockholm, Sweden. Tel.: +46 8 51776748; fax: +46851771806.

E-mail address: anna.lindblom@ki.se (A. Lindblom). mortality to below $5 \% .{ }^{1}$ As a consequence, this patient group is under high antibiotic pressure and risks both the selection of and colonization by fungi and multi-resistant bacteria. Viral infections, especially respiratory viral pathogens, account for significant morbidity in children in general. It is therefore likely that an overrepresentation of viral infections is also present during febrile episodes in children with neutropenia. However, diagnostic and therapeutic options are scarce and have not motivated extensively investigation. Causative agents are only detected in 15-30\% of the cases, and an etiological search of microbiological agents during febrile neutropenic episodes is required to strengthen the clinical management of this group of patients. ${ }^{2,3}$

\section{Objective}

The objective with the study was to investigate viruses role as possible etiological agents in children under cancer treatment presenting with neutropenic fever. 


\section{Study design}

The study was conducted at the pediatric oncology units at the Children's Hospital at Westmead, Sydney, Australia, and Astrid Lindgren Children's Hospital at the Karolinska University Hospital, Stockholm, Sweden, respectively. The study period was 1 year starting in January 2007. All children with a neutropenic febrile episode defined as an axillary temperature $>38.0^{\circ} \mathrm{C}$ on two occasions $60 \mathrm{~min}$ apart or $\geq 38.5^{\circ} \mathrm{C}$ at one occasion and an absolute neutrophil count $\leq 500$ cells $/ \mathrm{mm}^{3}$ were invited to participate in the study. After informed consent was obtained, paired nasopharyngeal aspirates (NPAs) and peripheral blood samples were collected. Blood cultures were obtained for routine laboratory assessments and additionally bacteria sampling was performed as guided by symptoms. Only the results from the blood cultures are presented in the study. Clinical data were extracted from the medical journals.

Conventional viral detection, immunofluoresence (IF) and viral culture, were performed at both the study sites respectively using the local accredited protocols. NPAs were initially analyzed by monoclonal antibodies and immunofluoresence (IF) detecting parainfluenzavirus (PIV), influenza (Flu) A and B virus, and respiratory syncytial virus (RSV). Viral cultures of NPA samples were monitored for cytopathic effect (CPE), with confirmatory IF performed on cultures with positive CPE. Pathogens detectable included herpes simplex virus (HSV) 1 and 2, varicella zoster virus (VZV), enterovirus (EV), RSV, adenovirus (AdV), PIV1-3, Flu A,B and CMV. Rhinovirus (HRV) was only detectable by viral culture within the Children's Hospital at Westmead's Laboratory.

For the detection of viral nucleic acid, NPAs and blood samples were batch analyzed at the Karolinska University Hospital using local accredited methods; total nucleic acid was extracted from NPAs and analyzed using real-time semi-quantitative PCR targeting a panel of respiratory viruses; RSV, Flu A and B, PIV 1-3, EV,
AdV, HRV, bocavirus (HBoV), metapneumovirus (hMPV), coronaviruses (CoV) NL63/OC43/229E/HKU1 and KI/WU polyomaviruses (KIPyV/WUPyV). ${ }^{4,5}$

Quantitative real-time PCR was also used for the DNA detection of CMV in total nucleotide extracted peripheral blood, AdV in total nucleotide extracted plasma, and EBV and human erythrovirus 1-3 in total nucleotide extracted serum and NPA.6,7 Bacterial analysis was performed by the Local Clinical Microbiology Laboratory by accredited methods after sampling as per normal clinical routines. The results of the expanded viral analyzes were not available to clinicians in real time.

Group comparisons were performed by Kruskal-Wallis test for clinical parameters (Graph Pad Software).

\section{Results}

In total, 130 patients were included in the study. Of them, 40 were excluded due to incomplete sampling $(n=19)$ and lack of material for PCR analyzes $(n=21)$. Hence, samples were processed from 90 episodes ( 47 and 43 from Stockholm and Sydney, respectively), obtained from 66 individuals. Of these, 53\% were females with a median age of 4.9 years (range $0.4-17.8$ years). Sixty-nine percent of the episodes were derived from patients undergoing treatment for a hematological malignancy and $31 \%$ for solid tumors. A median of eight episodes were included per month (range 1-10), with no apparent seasonality. Conventional assessment by viral culture and IF on NPA samples revealed 10 (11\%) episodes with the presence of one or more viral pathogen (six HRV, three CMV, and one PIV3), all identified at the Sydney study site. In addition, bacteremia was identified in 21 (23\%) episodes. In total, with a conventional virus-diagnostic approach, infectious agents were identified in 26 (29\%) episodes of febrile neutropenia.

Table 1

Microbiological findings by PCR.

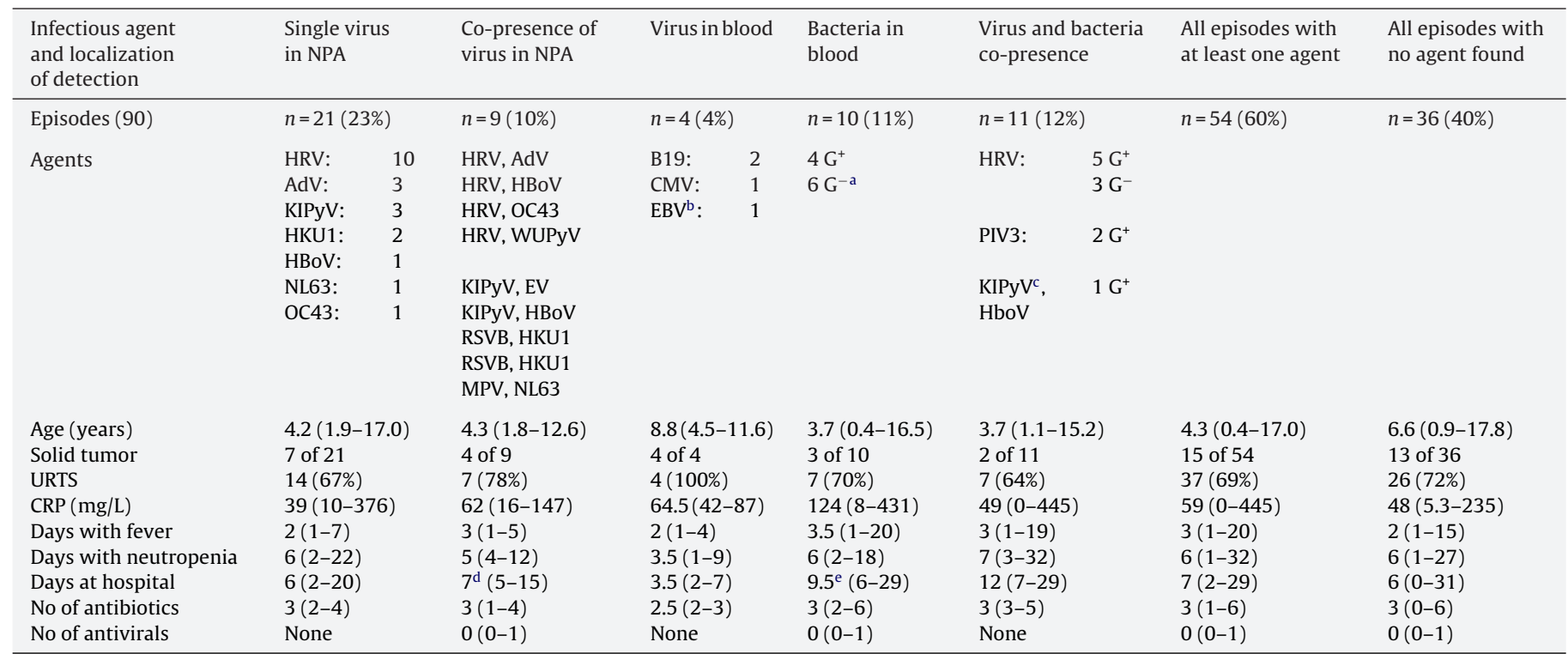

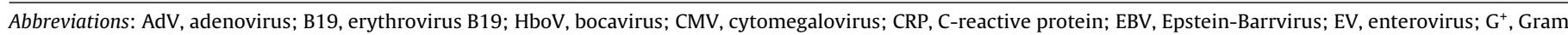

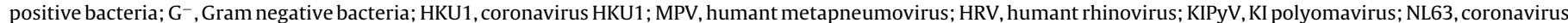

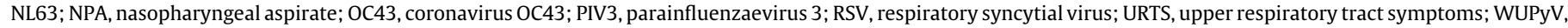
WU polyomavirus. Number of antibiotics and antivirals indicate the number of anti-infective drugs administered during in-patient care.

a One case with fatal outcome.

b Rhinovirus detected in NPA.

c Also presented in the "Co-presence of virus in NPA" group.

d Significantly larger number of days in hospital as compared to the group with virus in blood $(P<0.05)$ and episodes with no agent found $(<0.05)$.

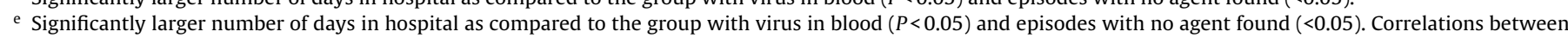
other clinical parameters were non-significant. 
Table 2

Comparison of molecular and conventional methods in the 22 episodes with virus detected to which capacity of detection overlapped.

\begin{tabular}{|c|c|c|c|}
\hline Virus detected & $\mathrm{PCR}(\mathrm{ct})$ & Culture & IF \\
\hline Adenovirus & $(36.95)$ & Not detected & $\mathrm{N} / \mathrm{A}^{\mathrm{a}}$ \\
\hline Adenovirus & (36.98) & Not detected & $\mathrm{N} / \mathrm{A}^{\mathrm{a}}$ \\
\hline Adenovirus & (38.66) & Not detected & $\mathrm{N} / \mathrm{A}^{\mathrm{a}}$ \\
\hline EV, KIPyV & (29.88), (33.7) & Not detected $/ N / A^{a}$ & $\mathrm{~N} / \mathrm{A}^{\mathrm{a}}$ \\
\hline HRV & (33.06) & Not detected & $\mathrm{N} / \mathrm{A}^{\mathrm{a}}$ \\
\hline HRV & $(35.41)$ & Not detected & $\mathrm{N} / \mathrm{A}^{\mathrm{a}}$ \\
\hline HRV & $(20.26)$ & HRV & $\mathrm{N} / \mathrm{A}^{\mathrm{a}}$ \\
\hline HRV & (34.68) & Not detected & $\mathrm{N} / \mathrm{A}^{\mathrm{a}}$ \\
\hline HRV & $(38.03)$ & HRV & $\mathrm{N} / \mathrm{A}^{\mathrm{a}}$ \\
\hline HRV & $(26.53)$ & Not detected & $\mathrm{N} / \mathrm{A}^{\mathrm{a}}$ \\
\hline HRV & $(24.95)$ & Not detected & $\mathrm{N} / \mathrm{A}^{\mathrm{a}}$ \\
\hline HRV & $(16.89)$ & HRV & $\mathrm{N} / \mathrm{A}^{\mathrm{a}}$ \\
\hline HRV, Aoca & $(32.71),(35.10)$ & $\mathrm{HRV}, \mathrm{N} / \mathrm{A}^{\mathrm{a}}$ & $\mathrm{N} / \mathrm{A}^{\mathrm{a}}$ \\
\hline HRV, CMV, WUPyV & (36.91), N/A, (26.7) & Not detected, CMV, N/A & $\mathrm{N} / \mathrm{A}^{\mathrm{a}}$ \\
\hline PIV3 & $(22.9)$ & Not done ${ }^{b}$ & PIV3 \\
\hline PIV3 & $(28.19)$ & Not detected & Not detected \\
\hline
\end{tabular}

a Detection not applicable with method.

b No culture done.

NPA samples were further evaluated using real-time PCR targeting the viruses detectable by culture (except for CMV) with the addition of agents not normally detected by culture (HBoV, hMPV, CoV, KIPyV, and WUPyVV). In addition to NPA, peripheral blood samples taken at enrollment were assessed for CMV, AdV, EBV and erythrovirus. The findings are shown in Table 1 . One or more viral pathogens were identified in 44 (49\%) episodes overall-in 41 (46\%) NPA samples and in 4 (4\%) peripheral blood samples. In total, infectious agents were identified in 54 (60\%) episodes of febrile neutropenia using a diagnostic approach which included PCRbased virus detection. There were no differences in the frequency of detected pathogens between the patients with a hematological malignancy and the ones with a solid tumor.

Twenty-two episodes had at least one virus detected to which capacity of detection overlapped between the conventional methods and real-time PCR, Table 2 . The conventional techniques could detect a virus in seven (29\%) of the 22 episodes with a median threshold cycle (Ct) of 24.4 (range 16.9-32.7). In the samples with a virus detected by only PCR, the median Ct was 33.4 (range 25-38.7).

Eight individuals had NPA sampled repeatedly during separate neutropenic fever episodes and were assessable to whether the virus had cleared or persisted by real-time PCR. Of these individuals, five demonstrated clearance (after a median of 5.5 weeks, range 2.7-14 weeks), while three had the same virus persistently detectable, two rhinovirus and one HKU1 (after a median of 3.6 weeks, range 3.4-5 weeks).

Differences in the clinical picture in patients with different detected pathogens and the group with no detected pathogens were sought for (Table 1 ). The only statistical significance recorded was longer hospitalization in the groups with bacteremia and copresence of virus in NPA and in the group with only bacteremia as compared to the groups with disseminated viral infection and with no microbial agent detected. One case with fatal outcome was recorded in the group with bacteria detected in blood.

\section{Discussion}

In this report we show that PCR-based viral diagnostics can greatly increase the detection of infectious agents in febrile episodes of neutropenia in children. The addition of assays detecting recently described viruses and viruses difficult to detect by conventional methods also contributed to higher detection rates. It was also noted that the use of a more extended viral culture routine including detection of HRV by one of our study laboratories clearly contributed to a higher yield of positive findings.

There are only a few previously reported studies with the aim of detecting a broad range of viruses in children with neutropenic fever in a pediatric oncology setting using PCR-techniques. Christensen et al. $^{8}$ reported a prospective study of a population of children on cancer treatment. They detected virus in $10 \%$ of oral washes and nasal swabs and noted severe infectious complications in these patients. Conversely, Koskenvuo et al. ${ }^{9}$ found evidence of viral infection in $44 \%$ of nasal swabs in children with leukemia with no significant association to neutropenia. In the present study we focused only on patients presenting with neutropenic fever and could confirm Koskenvuos ${ }^{9}$ high detection rate of respiratory tract viruses but also HRV as the most common detected pathogen. Differences in sampling procedures probably explain the discrepancy between the present study and the study by Christensen et al. ${ }^{8}$ Co-presence of a respiratory virus was detected in half of the episodes with bacteremia which also corresponds to what was found in a group of children with acute leukemia. ${ }^{10}$ Interestingly, no differences in the clinical picture and parameters were detected in our material except for longer hospitalization in the group of patients with bacteremia and co-presence of respiratory virus and bacteremia alone as compared to the groups with disseminated viral infection and with no microbial agent detected (Table 1). Whether this reflects a more severe clinical picture in group with co-detection of bacteremia and respiratory virus and bacteremia alone or a milder course in the group of patients with disseminated viral infection and no agent detected could not be ruled out in the study.

Utilizing PCR-techniques for viral detection has thus the advantage of increased sensitivity as compared to viral culture and antigen detection. It is however not clear whether the detected viral nucleic acid actually represents the direct causative agent of the neutropenic fever. A positive PCR result could also represent a sub-clinical infection, a post-infection viral shedding, or just intracellular non-replicating viral nucleic acid remnants. However, a recent prospective study on repeated sampling of infants showed that the same virus was detected in only $5 \%$ of consecutively sampled NPA after 2 weeks, and in these cases only rarely the same 
virus genotype. ${ }^{11}$ Prolonged viral shedding of RSV and influenza A has been reported in children with cancer. ${ }^{12,13}$ of 27 patients studied by Koskenvuo et al. ${ }^{9}$ whose follow-up samples were taken 1-11 days after the first one, 23 were negative whereas four patients remained virus-positive. In our present study, eight individuals had NPA sampled repeatedly during separate neutropenic fever episodes of which five demonstrated clearance. Whether the three patients remaining virus positive was due to a persistent infection or a new infection of a different genotype could not be ruled out since we did not perform sequencing. These patients were also sampled with a shorter interval and may have received stronger immunosuppression or represent a more severe underlying disease. However, as indicated by Koskenvuo et al. ${ }^{9}$ and our present study, the majority of viruses detected were eventually cleared, supporting the fact that the virus corresponds to an acute infection. In order to decrease the usage of broad spectrum antibiotics, the role of the detected viruses as causative agents needs to be further clarified in future studies by follow-up sampling but also inclusion of controls. It would also be helpful to study the meaning of different viral loads and their correlation to clinical disease.

Although disseminated CMV, EBV and AdV have been described as a major cause of morbidity and mortality in children undergoing hematopoietic stem-cell transplantation (HSCT), ${ }^{6}$ they have not been thoroughly assessed in children with neutropenia. In this study, these viruses were present in $4 \%$ of the febrile episodes and are thus not a significant cause of morbidity in this setting. This is most likely due to a less profound immunosuppression in the majority of these children as compared to patients undergoing HSCT. In the case of erythrovirus infection, it may also reflect the need to analyze bone marrow-samples to find persistent infection where peripheral viremia is low or absent. ${ }^{14}$

Several studies have tried to identify risk factors to single out the patients at highest risk of life threatening infections and in need of hospital care with broad spectrum antibiotics, and patients with lower risk and thereby suitable for less broad and even ambulatory treatment. ${ }^{15-18}$ By adding PCR-based viral diagnostics to the microbial investigation of children with neutropenic fever, we could greatly enhance the diagnostic sensitivity, but further studies are needed to address causality and viral load association to clinical disease in this group of patients. In the future, application of agile and broad microbial diagnostics may however provide decreased use of antibiotics and individualized infection-management in this group of patients.

\section{Conflicts of interest}

All authors declare that they have no conflicting interests.

\section{Acknowledgements}

We thank Ilona Lewensohn-Fuchs and Alison Kesson for expert advice and technical input. We will also like to thank the staff at The Children's Hospital at Westmead Tumour Bank for the help with sample preparation and storage. Biospecimens were provided by The Children's Hospital at Westmead Tumour Bank, a member of the Australasian Biospecimens Network-Oncology, which is supported by the National Health and Medical Research Council through a grant from the Cancer Institute of New South Wales.

Financial support for the study was received from The Swedish Children's Cancer Foundation, the Groschinsky Foundation and the Stockholm County Council. The study was approved by the Regional Ethical Review Board in Stockholm and Human Research Ethics Committee in Westmead.

\section{References}

1. Crokaert F. Febrile neutropenia in children. Int $J$ Antimicrob Agents 2000;16(October (2)):173-6.

2. Castagnola E, Fontana V, Caviglia I, Caruso S, Faraci M, Fioredda F, et al. A prospective study on the epidemiology of febrile episodes during chemotherapy-induced neutropenia in children with cancer or after hemopoietic stem cell transplantation. Clin Infect Dis 2007;45(November (10)):1296-304.

3. Hamidah A, Rizal AM, Nordiah AJ, Jamal R. Piperacillin-tazobactam plus amikacin as an initial empirical therapy of febrile neutropenia in paediatric cancer patients. Singapore Med J 2008;49(January (1)):26-30.

4. Lindau C, Tiveljung-Lindell A, Goh S, Ramqvist T, Allander T. A single-tube, realtime PCR assay for detection of the two newly characterized human KI and WU polyomaviruses. J Clin Virol 2008;(November).

5. Tiveljung-Lindell A, Rotzén-Ostlund M, Gupta S, Ullstrand R, Grillner L, Zweygberg-Wirgart B, et al. Development and implementation of a molecular diagnostic platform for daily rapid detection of 15 respiratory viruses. J Med Virol 2009;81(January (1)):167-75.

6. Gustafson I, Lindblom A, Yun Z, Omar H, Engstrom L, Lewensohn-Fuchs I, et al. Quantification of adenovirus DNA in unrelated donor hematopoietic stem cell transplant recipients. J Clin Virol 2008;43(September (1)):79-85.

7. Lindblom A, Isa A, Norbeck O, Wolf S, Johansson B, Broliden K, et al. Slow clearance of human parvovirus B19 viremia following acute infection. Clin Infect Dis 2005:41(October (8)):1201-3.

8. Christensen MS, Nielsen LP, Hasle H. Few but severe viral infections in children with cancer: a prospective RT-PCR and PCR-based 12-month study. Pediatr Blood Cancer 2005;45(December (7)):945-51.

9. Koskenvuo M, Möttönen M, Rahiala J, Saarinen-Pihkala UM, Riikonen P, Waris $\mathrm{M}$, et al. Respiratory viral infections in children with leukemia. Pediatr Infect Dis J 2008; (October).

10. Koskenvuo M, Möttönen M, Rahiala J, Saarinen-Pihkala UM, Riikonen P, Waris $\mathrm{M}$, et al. Mixed bacterial-viral infections in septic children with leukemia. Pediatr Infect Dis J 2007;26(December (12)):1133-6.

11. Jartti T, Lee WM, Pappas T, Evans M, Lemanske Jr RF, Gern JE. Serial viral infections in infants with recurrent respiratory illnesses. Eur RespirJ 2008;32(August (2)):314-20.

12. Craft AW, Reid MM, Gardner PS, Jackson E, Kernahan J, McQuillin J, et al. Virus infections in children with acute lymphoblastic leukaemia. Arch Dis Child 1979;54(October (10)):755-9.

13. Hall CB, Powell KR, MacDonald NE, Gala CL, Menegus ME, Suffin SC, et al. Respiratory syncytial viral infection in children with compromised immune function. N Engl J Med 1986;315(July (2)):77-81.

14. Lindblom A, Heyman M, Gustafsson I, Norbeck O, Kaldensjö T, Vernby A, et al. Parvovirus B19 infection in children with acute lymphoblastic leukemia is associated with cytopenia resulting in prolonged interruptions of chemotherapy. Clin Infect Dis 2008;46(February (4)):528-36.

15. Petrilli AS, Dantas LS, Campos MC, Tanaka C, Ginani VC, Seber A. Oral ciprofloxacin vs. intravenous ceftriaxone administered in an outpatient setting for fever and neutropenia in low-risk pediatric oncology patients: randomized prospective trial. Med Pediatr Oncol 2000;34(February (2)):87-91.

16. Freifeld A, Marchigiani D, Walsh T, Chanock S, Lewis L, Hiemenz J, et al. A doubleblind comparison of empirical oral and intravenous antibiotic therapy for lowrisk febrile patients with neutropenia during cancer chemotherapy. $N$ Engl J Med 1999;341(July (5)):305-11.

17. Santolaya ME, Alvarez AM, Avilés CL, Becker A, Cofré J, Cumsille MA, et al. Early hospital discharge followed by outpatient management versus continued hospitalization of children with cancer, fever, and neutropenia at low risk for invasive bacterial infection. J Clin Oncol 2004;22(September (18)):3784-9.

18. Oude Nijhuis C, Kamps WA, Daenen SM, Gietema JA, van der Graaf WT Groen $\mathrm{HJ}$, et al. Feasibility of withholding antibiotics in selected febrile neutropenic cancer patients. J Clin Oncol 2005;23(October (30)):7437-44. 